\title{
Análisis de los contenidos de arquitectura en la prensa digital española. El caso de ABC.es en 2019
}

\section{An analysis of architecture-related content in the Spanish digital press. The case of ABC.es in 2019}

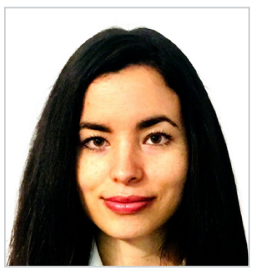

Marina Fernández Maestre. Arquitecta por la Escuela Técnica Superior de Arquitectura de Sevilla (ETSAS). Ha cursado su último año de arquitectura en la Technische Universität de Berlin. Tiene, además, un máster en Periodismo Cultural por la Universidad CEU San Pablo de Madrid. Actualmente es doctoranda en la Facultad de Ciencias de la Información de la Universidad Complutense de Madrid, donde investiga sobre periodismo especializado en arquitectura y artes visuales. Ha escrito sobre arte y arquitectura en revistas especializadas como Arquitectura Viva o T Spain-The New York Times Style Magazine. Es fundadora de la página web Expoartemadrid (www.expoartemadrid.com), centrada en los eventos de arte y arquitectura de la capital.

Universidad Complutense de Madrid, España

marinf40@ucm.es

ORCID: 0000-0002-7212-5131

Recibido: 15/10/2020 - Aceptado: 21/02/2021

\section{Resumen:}

La presente investigación analiza los textos de arquitectura publicados en la versión digital del diario $A B C$, es decir, en $A B C$.es, a lo largo del año 2019. El principal objetivo de este estudio ha sido conocer en profundidad el tratamiento de estos contenidos en uno de los diarios de tirada nacional de mayor antigüedad de España. La técnica metodológica utilizada ha sido el análisis de contenido. La muestra seleccionada está integrada por los 117 textos etiquetados como "Arquitectura" y publicados entre los meses de enero y junio del año 2019, que han sido analizados en función de las siguientes variables: la sección de la web en la que se localiza el texto, el género periodístico, el tipo de obra arquitectónica o evento de arquitectura sobre el que trata, el nombre de cada autor (especificando el perfil profesional de los que más escriben), así como el número de imágenes, galerías de imágenes y vídeos que los acompañan. Los resultados más esclarecedores para conocer en profundidad el tratamiento de los contenidos han sido los extraídos del análisis del género periodístico del texto y del tipo de obra arquitectónica. Entre las conclusiones destaca la poca presencia de la crítica de arquitectura en ABC.es.

\section{Palabras clave:}

Periodismo cultural; periodismo digital; Arquitectura; crítica de arquitectura; $A B C . e s$
Received: 15/10/2020 - Accepted: 21/02/2021

\section{Abstract:}

This study has analysed architectural texts published in 2019 in the digital version of the newspaper $A B C$, which is $A B C . e s$. The main objective of the research is to gain in-depth knowledge into the coverage of this content in one of the oldest national newspapers in Spain. The methodological technique used has been content analysis. The selected sample consists of 117 texts in the category of "Architecture" published between January and June of 2019, which have been analysed according to the following variables: the section of the website where the text is located, the journalistic genre, the type of architectural work or event addressed, the name of each author (specifying the professional profile of the most prolific writers), as well as the number of images, image galleries, and videos accompanying each text. The most enlightening results for gaining in-depth knowledge into the coverage of the content are those obtained from the analyses of the journalistic genre of the text and the type of architectural work. Among the conclusions, one that stands out is the scarce presence of architectural criticism in ABC.es.

\section{Keywords:}

Cultural Journalism; digital journalism; Architecture; architecture criticism; ABC.es.

\footnotetext{
Cómo citar este artículo:

Fernández Maestre, M. (2021). Análisis de los contenidos de arquitectura en la prensa digital española. El caso de $A B C$.es en 2019. Doxa Comunicación, 32, pp. 431-450.
}

https://doi.org/10.31921/doxacom.n32a20 


\section{Introducción}

\subsection{Estado de la cuestión}

La arquitectura es una disciplina de gran repercusión social que se nutre, y depende al mismo tiempo, de materias muy diversas, como la política, la economía, la tecnología, la ecología o la sociología. Sin embargo, a pesar del gran impacto que tiene en la vida de los ciudadanos, las investigaciones que se han realizado sobre la arquitectura desde un enfoque periodístico-cultural son muy escasas. Por este motivo, es tan necesario realizar un estudio que profundice en el tratamiento que reciben en prensa estos contenidos.

Los textos dedicados a la arquitectura forman parte del periodismo cultural y, por ello, suelen estar localizados en la sección de cultura de los diarios y en sus suplementos culturales. La función de la sección de cultura consiste en "canalizar la información que se genera en torno al mundo de la cultura y en darle un tratamiento homogéneo como especialidad diferenciada, difundiendo esa información con el fin de que llegue a los consumidores habituales de otro tipo de noticias" (Rodríguez Pastoriza, 2006: 10). En cambio, los suplementos de periodicidad semanal se reservan para publicar aquellos textos que se despegan de la actualidad informativa e invitan a la reflexión de la mano de expertos y de periodistas que recurren a fuentes especializadas. Por consiguiente,

Las rutinas de producción de información especializada se alejan ostensiblemente de las rutinas y los tiempos que imponen las fuentes oficiales y priorizan el contraste y verificación de los datos informativos que distribuyen las grandes agencias de noticias a la inmediatez que impone el periodismo generalista (Quesada, 2012: 71).

De esta manera, los suplementos culturales desempeñan un papel fundamental a la hora de poner criterio dentro del ecosistema cultural, ya que todavía gozan de un modo de ejercer la práctica periodística más pausado que posibilita el contraste y la verificación de los datos transmitidos por las fuentes oficiales, es decir, por las fuentes interesadas. Y es que no podemos olvidar que:

En la sociedad actual, con los espectáculos bien programados para el público masivo, el entretenimiento mueve mucho dinero, lo que refuerza su peso en la sociedad de la información. La consecuencia más inmediata es su importancia en la agenda de los medios que, además de las autopromociones, ofrecen una gran variedad de contenidos sobre espectáculos y sobre todo lo relacionado con el amplio abanico del entretenimiento. Así surgen los productos ligeros, la información de escasa profundidad y la variada oferta de mensajes para el consumo rápido y con el mínimo esfuerzo (Xosé López, 2004: 383).

Desgraciadamente la publicidad y los patrocinios tienen cada vez más peso a la hora de marcar e introducirse en la agenda cultural de los periódicos, una situación que se ha incrementado aún más, y es claramente visible, en las versiones digitales y en los diarios nativos digitales. Además, estos textos se ven afectados por otra mala práctica propia de la red: el clickbait, que ha fomentado que la prensa digital publique cada vez titulares más tendenciosos y priorice el número de visitas frente a la propia calidad de los contenidos. Por lo general, los textos de los suplementos culturales están más protegidos de esta tendencia, aunque lamentablemente el número de este tipo de publicaciones es cada vez más reducido en todos los diarios. No obstante, "los medios escritos tradicionales no renuncian a ellos como plataformas de prestigio, pero los toman más como una herramienta de agitación cultural y reflejo de creación que otra cosa” (Ruiz Mantilla y Garbisu 
Buesa, 2019: 29). En este punto es preciso hacer énfasis en que los suplementos culturales solo existen en los medios tradicionales, es decir, que ninguno de los periódicos españoles nativos digitales cuenta con un suplemento cultural y, de hecho, algunos de estos últimos tienen una sección de cultura muy pobre, que resulta incomparable con la de cualquiera de los periódicos tradicionales. Sin embargo, como afirma el profesor Xosé López (2004), los medios no deben olvidar que:

Aquellos que quieran ofrecer productos que contengan información de calidad de la sociedad actual difícilmente podrán prescindir de una buena sección de cultura o de un departamento de información cultural. Aunque esta información no figura entre los puntos fuertes de la mayoría de los medios de comunicación, que conceden un número limitado de páginas o espacios muy reducidos para el mundo cultural, lo cierto es que los ciudadanos más exigentes demandan contenidos culturales de calidad en los flujos informativos de cada día (389).

Entre los contenidos culturales de los medios es fundamental que esté presente la arquitectura, más aún, cuando su misión como obra artística y funcional es dar respuesta a una necesidad social. El crítico de arquitectura Paul Goldberger -ganador del Premio Pulitzer por Crítica en el año 1984 por sus artículos publicados en The New York Times- relacionó estas tres cuestiones (arte, función y fin social) en su libro Por qué importa la arquitectura (2012) de la siguiente manera:

La arquitectura como arte surge del deseo de hacer algo más que resolver un problema funcional. En cierto sentido, este deseo más profundo es por sí mismo la función ética de la arquitectura, una declaración de que el arte de un edificio existe no solo por el bien del arte, no se trata del arte por el arte, sino del arte con una finalidad social (76).

Sin embargo, esta función ética de la arquitectura descrita por Goldberger, en algunas ocasiones, no es el motor y el enfoque desde el que se escriben los textos publicados en los periódicos. Y menos aún en el ecosistema digital donde a veces el propio texto tiene menos importancia que las imágenes, llegando incluso a ser utilizado exclusivamente para la descripción de las mismas. Sucede, entonces, que la arquitectura aparece en algunos artículos ensombrecida por la frivolidad, como una cuestión meramente superficial, sin ser siquiera el elemento central. Pero los medios no pueden olvidarse de que esta disciplina de gran complejidad implica siempre la creación de un espacio social y, por tanto, debe ser explicada con rigor, ya que tiene una gran influencia en la vida de los ciudadanos.

\subsection{Objetivos}

La presente investigación analiza los contenidos de arquitectura en la prensa digital española, concretamente, aquellos publicados a lo largo del año 2019 en la página web del diario $A B C$. Como ya se ha mencionado anteriormente, los textos dedicados a esta materia forman parte del periodismo cultural. No obstante, aunque muchos de ellos se encuentran en la sección de cultura del diario o en su suplemento cultural-ABC Cultural-, también están presentes en otras secciones como Madrid, España, Viajar (y, de manera menos frecuente, en otras como Familia, Opinión, Ciencia, Internacional); en los blogs del diario y en Summum, el portal de tendencias, moda y ocio.

El principal objetivo de este estudio ha sido analizar en profundidad el estado de los textos etiquetados como "Arquitectura" en $A B C$.es, a fin de conocer el tratamiento periodístico de estos contenidos en el diario. Pero, además, esta investigación quiere poner en valor el beneficio que supone la divulgación de la arquitectura en prensa para que los ciudadanos creen lazos afectivos con el entorno y, por consiguiente, tengan un mayor interés por su preservación. Y es que la prensa, 
en su labor de servicio público, no puede olvidarse de la realidad innegable que describe Alexandra Lange (2012), colaboradora de periódicos como The New York Times o la revista The New Yorker y crítica de arquitectura en el portal Curbed:

Buildings are everywhere, large and small, ugly and beautiful, ambitious and dumb. We walk among them and live inside them, largely passive dwellers in cities of towers, houses, open spaces and shops we had no hand in creating. But we are their best audience. Owners, clients and residents come and go, but architecture lives on, acting a role in the life of the city and its citizens long after the original players are gone (8).

[Los edificios están por todas partes, grandes y pequeños, feos y hermosos, ambiciosos y mudos. Caminamos entre ellos y vivimos dentro de ellos, habitantes en su mayoría pasivos en ciudades de torres, casas, espacios abiertos y tiendas, en cuya creación no estuvimos involucrados. Pero somos su mejor público. Los propietarios, clientes y residentes van y vienen, pero la arquitectura sigue viviendo, desempeñando un papel en la vida de la ciudad y en sus ciudadanos mucho después de que los actores originales se hayan ido].

La arquitectura vive muchos más años que nosotros, a veces incluso durante varios siglos, como los monumentos de épocas antiguas que hoy en día constituyen un valioso patrimonio y despiertan interés cultural en ciudadanos de todo el mundo. Por este motivo, es vital que los medios no solo informen sobre arquitectura, sino que además la valoren de manera rigurosa y seleccionen sus contenidos con propiedad.

\section{Metodología}

La técnica metodológica utilizada en esta investigación ha sido el análisis de contenido. Primeramente, se ha seleccionado el medio, ABC.es, y el periodo de estudio, el año 2019. Después, se ha elegido centrar la investigación en todos los textos de este periodo etiquetados como "Arquitectura", que aparecen publicados en la dirección: https://www.abc.es/ cultura/arte/arquitectura. En la siguiente imagen [Fig.1] se puede observar la apariencia web de la etiqueta "Arquitectura" (además, dichos textos tienen siempre otras etiquetas más, por ejemplo, en este caso, “Edificios” y “Premio Pritzker”).

Figura 1. Ejemplo de la etiqueta "Arquitectura" que figura al final de los textos en $A B C . e s$

TEMAS

\section{Premio Pritzker Edificios Arquitectura}

En este punto hay que precisar, que el diario publica también textos con otras etiquetas relacionadas con la arquitectura como, por ejemplo, “Urbanismo", “Obras”, “Vivienda”, "Monumentos”, sin embargo, no todos ellos se etiquetan también como "Arquitectura”. Debido a que la arquitectura es una actividad tan diversa y compleja, y su ejercicio está íntimamente ligado a otras disciplinas, no siempre es fácil marcar una línea divisoria a la hora de realizar una clasificación. No obstante, la dirección del enlace bajo el que $A B C$.es publica sus contenidos etiquetados como "Arquitectura" (detallada en el párrafo anterior), revela que el periódico entiende la disciplina como una creación de autor y desde un enfoque artístico-cultural. De hecho, al realizar este análisis se ha observado que el diario prima estas cuestiones a la hora de incluir los 
textos bajo la etiqueta "Arquitectura", relegando algunos de los ellos a las otras etiquetas antes mencionadas. Por tanto, aunque estén vinculados a la arquitectura, el diario asocia estos textos a otros campos como, por ejemplo, las infraestructuras o la economía. Por este motivo, es necesario subrayar que esta investigación se ha centrado en el análisis de los textos con la etiqueta "Arquitectura" que han sido publicados en la web durante dicho periodo. En la Tabla 1, aparece detallada la cifra mes a mes y en total:

Tabla 1. Textos de "Arquitectura" publicados cada mes en ABC.es en 2019

\begin{tabular}{|c|c|c|c|c|c|c|c|c|c|c|c|c|}
\hline \multicolumn{10}{|c|}{ Número de textos con la etiqueta “Arquitectura" en ABC.es en 2019} \\
\hline Ene. & Feb. & Mar. & Abr. & May. & Jun. & Jul. & Ago. & Sep. & Oct. & Nov. & Dic. & Total \\
\hline 14 & 11 & 23 & 22 & 27 & 20 & 19 & 12 & 16 & 21 & 22 & 21 & 228 \\
\hline
\end{tabular}

Fuente: elaboración propia

Como se muestra en la Tabla 1, el diario ha publicado 228 textos etiquetados como "Arquitectura" a lo largo de todo el año. Concretamente, en este artículo se realiza un análisis en profundidad de los 117 publicados en el primer semestre, entre los meses de enero y junio. La técnica metodológica utilizada ha sido el análisis de contenido teniendo en cuenta las siguientes variables (que guardan relación directa con el objetivo principal de la presente investigación): la sección de la web en la que se localizan, el género periodístico, el tipo de obra arquitectónica o evento de arquitectura sobre el que se ha escrito, los nombres de los autores y el perfil profesional de los que más han publicado, así como los recursos utilizados para ilustrar cada texto: las imágenes, las galerías de imágenes y los vídeos.

\section{Resultados}

A continuación, se expone el análisis de la muestra de 117 textos en base a las variables indicadas en el apartado anterior.

\subsection{Localización de los contenidos de arquitectura}

En la sección de cultura de $A B C$ y en su suplemento $A B C$ Cultural se han publicado 46 textos etiquetados como "Arquitectura" -25 y 21 respectivamente- en el primer semestre del año 2019, como se puede observar en la Tabla 2 junto al número de publicaciones realizadas en el resto de secciones. 
Tabla 2. Localización de los textos de “Arquitectura" en ABC.es en 2019

\begin{tabular}{|l|c|c|c|c|c|c|c|}
\hline $\begin{array}{l}\text { Secciones de los textos de } \\
\text { “Arquitectura" en 2019 }\end{array}$ & Enero & Febrero & Marzo & Abril & Mayo & Junio & Total \\
\hline Cultura & 2 & 1 & 3 & 8 & 5 & 6 & $\mathbf{2 5}$ \\
\hline ABC Cultural & 3 & 1 & 3 & 6 & 7 & 1 & $\mathbf{2 1}$ \\
\hline Madrid & 4 & 4 & 7 & 6 & 7 & 5 & $\mathbf{3 3}$ \\
\hline España & 0 & 2 & 3 & 1 & 3 & 2 & $\mathbf{1 1}$ \\
\hline Summum & 2 & 1 & 1 & 0 & 1 & 1 & $\mathbf{6}$ \\
\hline Viajar & 2 & 2 & 6 & 0 & 4 & 2 & $\mathbf{1 6}$ \\
\hline Familia & 1 & 0 & 0 & 0 & 0 & 0 & $\mathbf{1}$ \\
\hline Opinión & 0 & 0 & 0 & 1 & 0 & 0 & $\mathbf{1}$ \\
\hline Ciencia & 0 & 0 & 0 & 0 & 0 & 2 & $\mathbf{2}$ \\
\hline Internacional & 0 & 0 & 0 & 0 & 0 & 1 & $\mathbf{1}$ \\
\hline Total & $\mathbf{1 4}$ & $\mathbf{1 1}$ & $\mathbf{2 3}$ & $\mathbf{2 2}$ & $\mathbf{2 7}$ & $\mathbf{2 0}$ & $\mathbf{1 1 7}$ \\
\hline
\end{tabular}

Fuente: elaboración propia

Tanto en la sección de cultura como en ABC Cultural, la mayoría de los temas guardan relación con la actualidad, aunque en la primera también encontramos textos tipo test sobre edificios para "poner a prueba los conocimientos de arquitectura del lector" (como se detalla literalmente en la página). No obstante, Madrid es la sección en la que más textos de arquitectura se han publicado: 33, muchos de los cuales son reportajes sobre representativos edificios históricos de la ciudad. El cuarto lugar lo ocupa Viajar con 16 textos, la mayoría sobre destacados monumentos de distintos países del mundo. En quinta posición está la sección España, con 11 textos, donde encontramos textos sobre edificios o eventos que tienen lugar en distintos puntos del país. Y en sexto puesto, Summum con seis publicaciones que, sin embargo, no tienen como fin informar o valorar la arquitectura, sino anunciar el precio que tienen las mansiones de los famosos y su estilo de vida. En el resto de secciones, la disciplina aparece de manera muy reducida, con tan solo uno o dos textos. En este punto es preciso aclarar que, en el menú de temas de arquitectura, no aparecen los textos del blog de $A B C$ titulado $L a$ viga en el ojo, dedicado a esta disciplina y fundado por el crítico Fredy Massad en el año 2013. No obstante, la cifra total de textos etiquetados como "Arquitectura" apenas cambiaría, ya que si se consulta el blog se comprueba que solo hay un texto publicado en el primer semestre del año 2019.

A partir de los datos totales de la Tabla 2 se ha elaborado el Gráfico 1 para conocer de manera visual el porcentaje de textos de arquitectura publicados en las distintas secciones. 
Gráfico 1. Localización de los textos de “Arquitectura” en ABC.es en 2019

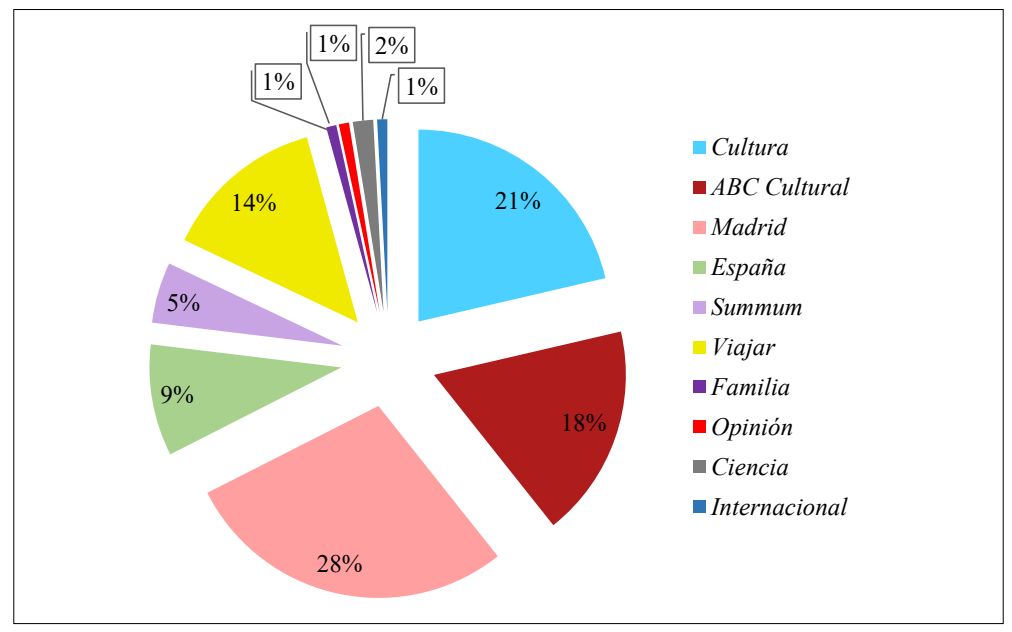

Fuente: elaboración propia

Como se observa en el Gráfico 1, la sección Cultura-21\%-y ABC Cultural-18\%-suman un 39\%, y junto a Madrid, un 67\%, por lo que entre las tres engloban más de dos tercios del volumen total de los textos publicados en el semestre. En cuarta posición, está Viajar con un 14\%. El quinto y el sexto lugar lo ocupan España y Summum, con un 9\% y un 5\% respectivamente. El resto de secciones representan un porcentaje muy reducido, menos del $2 \%$.

\subsection{Tipo de obra o evento de arquitectura}

A pesar de que la arquitectura ya es un contenido muy específico en prensa, conviven dentro de los textos etiquetados como "Arquitectura" en $A B C$.es distintas materias. Para este estudio se han creado ex profeso ocho categorías, que definen de manera más detallada el tipo de obra o evento de arquitectura de los textos y que son independientes de las etiquetas del diario. A continuación, se indican todas ellas en la Tabla 3. 
Tabla 3. Tipo de obra o evento de los textos de "Arquitectura" de ABC.es en 2019

\begin{tabular}{|l|c|c|c|c|c|c|c|}
\hline $\begin{array}{l}\text { Obra o evento de los textos de } \\
\text { "Arquitectura" de } A \text { BC.es 2019 }\end{array}$ & Enero & Febrero & Marzo & Abril & Mayo & Junio & Total \\
\hline Edificios & 5 & 2 & 9 & 7 & 10 & 6 & $\mathbf{3 9}$ \\
\hline Urbanismo & 0 & 0 & 1 & 1 & 0 & 0 & $\mathbf{2}$ \\
\hline Patrimonio & 4 & 4 & 7 & 6 & 9 & 9 & $\mathbf{3 9}$ \\
\hline Interiorismo & 2 & 0 & 0 & 0 & 1 & 0 & $\mathbf{3}$ \\
\hline Diseño & 0 & 1 & 1 & 0 & 0 & 1 & 3 \\
\hline Exposiciones & 1 & 2 & 2 & 6 & 2 & 2 & $\mathbf{1 5}$ \\
\hline Arquitectos & 2 & 1 & 3 & 1 & 4 & 1 & $\mathbf{1 2}$ \\
\hline Otros & 0 & 1 & 0 & 1 & 1 & 1 & $\mathbf{4}$ \\
\hline Total & $\mathbf{1 4}$ & $\mathbf{1 1}$ & $\mathbf{2 3}$ & $\mathbf{2 2}$ & $\mathbf{2 7}$ & $\mathbf{2 0}$ & $\mathbf{1 1}$ \\
\hline
\end{tabular}

Fuente: elaboración propia

Como se puede ver en la Tabla 3, los textos más populares son aquellos que tratan sobre "Edificios" y "Patrimonio", ambas categorías con 39 publicaciones. En tercera posición figuran los textos sobre exposiciones, 15 en total, y en cuarta, aquellos centrados en la figura del arquitecto, 12 en total. Del resto de categorías hay un número reducido de publicaciones: cuatro de "Otros" -en la que se han incluido aquellos que no tienen como fin informar o valorar la arquitectura-, tres de "Interiorismo" y "Diseño", y tan solo dos de "Urbanismo".

A partir de los datos totales de la Tabla 3, se ha elaborado el Gráfico 2 para conocer de manera visual el porcentaje que representa cada una de las categorías en las que se han clasificado los contenidos de los textos etiquetados como "Arquitectura".

Gráfico 2. Clasificación de los textos de “Arquitectura" de ABC.es en 2019

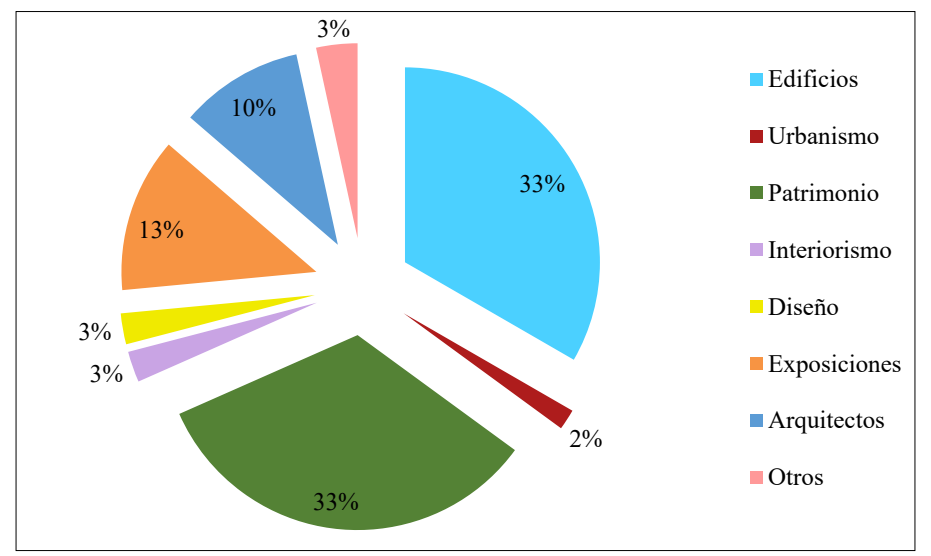

Fuente: elaboración propia 
Como se observa en el Gráfico 2, los mayores porcentajes pertenecen a los textos que tratan sobre edificios y patrimonio, suponiendo cada uno de ellos un 33\%, por lo que la suma de ambos equivale prácticamente a dos tercios del total. En tercer y cuarto lugar figuran los textos dedicados a las exposiciones y a los propios arquitectos, representado un $13 \%$ y un $10 \%$ respectivamente. Los porcentajes de las categorías “Interiorismo", "Diseño", "Urbanismo” y “Otros” son muy reducidos, todos ellos iguales o inferiores al $3 \%$.

\subsection{Géneros periodísticos}

Otro análisis importante en esta investigación ha sido conocer el género periodístico que determina la finalidad de cada texto. Para este estudio se han seguido las definiciones que recoge el periodista Álex Grijelmo en su libro El estilo del periodista (2014). En la Tabla 4 se muestra el número de textos por género periodístico, mes a mes y en total. Además, en esta investigación se ha creado la categoría “Otros” para incluir los textos tipo test y los construidos a base de galerías de imágenes (es decir, añadiendo unas pocas frases debajo de cada imagen).

Tabla 4. Géneros de los textos de "Arquitectura" de ABC.es en 2019

\begin{tabular}{|l|c|c|c|c|c|c|c|}
\hline $\begin{array}{l}\text { Géneros de los textos de } \\
\text { “Arquitectura" de } A \text { BC.es en 2019 }\end{array}$ & Ene. & Feb. & Mar. & Abr. & May. & Jun. & Total \\
\hline Noticia & 4 & 7 & 10 & 7 & 9 & 8 & $\mathbf{4 5}$ \\
\hline Reportaje & 4 & 3 & 5 & 7 & 4 & 4 & $\mathbf{2 7}$ \\
\hline Entrevista & 2 & 0 & 2 & 2 & 0 & 2 & $\mathbf{8}$ \\
\hline Reseña & 0 & 1 & 0 & 0 & 0 & 0 & $\mathbf{1}$ \\
\hline Crítica & 1 & 0 & 1 & 2 & 1 & 1 & $\mathbf{6}$ \\
\hline Artículo & 0 & 0 & 2 & 1 & 8 & 3 & $\mathbf{1 4}$ \\
\hline Otros & 3 & 0 & 3 & 3 & 5 & 2 & $\mathbf{1 6}$ \\
\hline Total & $\mathbf{1 4}$ & $\mathbf{1 1}$ & $\mathbf{2 3}$ & $\mathbf{2 2}$ & $\mathbf{2 7}$ & $\mathbf{2 0}$ & $\mathbf{1 1 7}$ \\
\hline
\end{tabular}

Fuente: elaboración propia

Como se muestra en la Tabla 4, la mayoría de los textos de arquitectura son noticias, 45 en total. Otro género que también abunda es el reportaje, con 27 textos. En tercera y cuarta posición figuran los textos etiquetados como “Otros” y los artículos, con 16 y 14 respectivamente. En quinto y sexto lugar, la entrevista y la crítica, con 8 y 6 publicaciones respectivamente. Finalmente, la reseña apenas aparece, solamente una vez en todo el semestre.

A partir de los datos totales de la Tabla 4 se ha elaborado el Gráfico 3 para conocer de manera visual el porcentaje que representa cada uno de los géneros. 
Gráfico 3. Géneros de los textos de "Arquitectura” en ABC.es en 2019

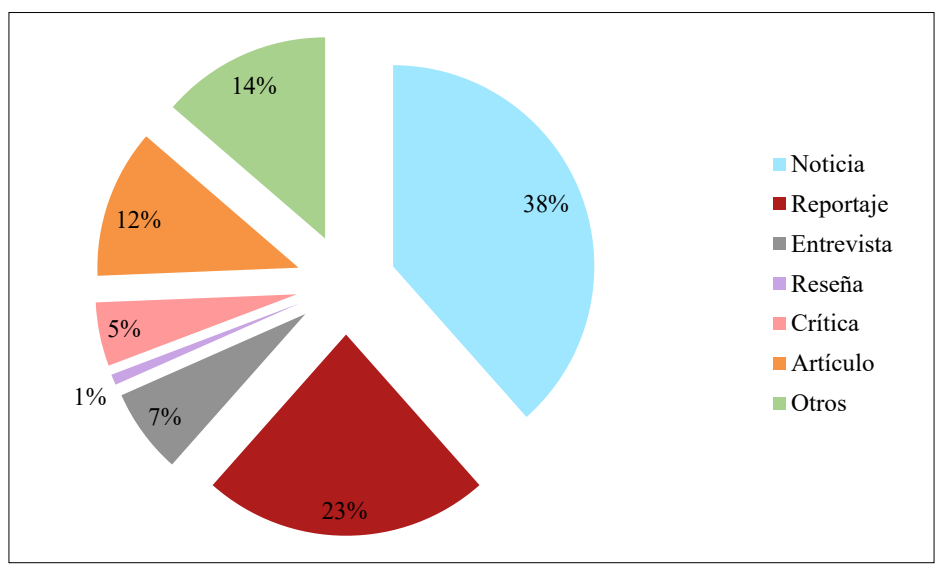

Fuente: elaboración propia

Como se observa en el Gráfico 3, los dos géneros con mayor porcentaje son las noticias (38\%) y los reportajes (23\%), que suman en total un $61 \%$, constituyendo casi dos tercios del volumen total. La tercera y la cuarta posición la ocupan el tipo de textos clasificados como "Otros" y los artículos, con un $14 \%$ y un $12 \%$ respectivamente. En quinto y sexto lugar figuran la entrevista y la crítica, que suponen el $7 \%$ y el $5 \%$ de los textos, respectivamente. Y, por último, la reseña que tan solo representa un $1 \%$.

En este punto es preciso decir que el género por excelencia del periodismo generalista es la noticia, definida como "la esencia del periodismo, la materia prima. La noticia en estado puro tiene su origen en un acontecimiento sorprendente, estremecedor, paradójico o trascendental y, sobre todo, reciente" (Grijelmo, 2014: 29). Por el contrario, un género propio del periodismo especializado es la crítica, donde el profesional "analiza y desmenuza una obra artística o cultural. Es un texto claramente opinativo, que incluye información que enmarca y explica la obra además del juicio que al crítico le merece" (Grijelmo, 2014: 112). La presencia de este último tipo de textos, que analizan una obra arquitectónica e invitan a la reflexión, es de vital importancia dentro del periodismo cultural. Como describe el arquitecto y profesor Josep Maria Montaner (2013),

La crítica comporta un juicio estético. Dicho juicio consiste en una valoración individual de la obra arquitectónica que el crítico realiza a partir de la complejidad del bagaje de conocimientos de que dispone, de la metodología de la que hace uso, de su capacidad analítica y sintética, y también de su sensibilidad, intuición y gusto (7).

Además, Montaner (2013) concreta que, en el caso de la arquitectura, el juicio se establece en base a si la obra "ha alcanzado sus finalidades: funcionalidad distributiva y social, belleza y expresión de símbolos y significados, adecuado uso de los materiales y técnicas, relación con el contexto urbano, el lugar y el medio ambiente" (11). También Golberger (2007) insiste en que el crítico de arquitectura debe juzgar la obra en base a su contexto social y político precisando que: 
A critic can and should establish a set of social and political principles that define his judgment, and act as a foundation for his criticism. The challenge is to hold onto these principles and at the same time to remain open to a broader range of aesthetic responses to these principles than any one architect might have, and then to be able to judge these different aesthetic responses on their own terms. I believe architecture exists in a social and political context, and almost always needs to be judged within that context (párr. 15).

[Un crítico puede y debe establecer un conjunto de principios sociales y políticos que definan su juicio, y actúen como fundamento de su crítica. El reto es aferrarse a esos principios y al mismo tiempo permanecer abiertos a una gama más amplia de respuestas estéticas a esos principios que cualquier arquitecto podría tener, y luego ser capaz de juzgar estas diferentes respuestas estéticas en sus propios términos. Creo que la arquitectura existe en un contexto social y político, y casi siempre necesita ser juzgada dentro de ese contexto].

\subsubsection{La importancia de la crítica y los críticos}

La crítica está presente en solo un 5\% de los textos etiquetados como “Arquitectura” en ABC.es a lo largo del primer semestre del 2019. Un porcentaje escaso, más aún en un periódico de tirada nacional. Ya en el año 2010, Alexandra Lange advertía sobre el peligro que corre la crítica de arquitectura en los medios, asegurando que, si no se remedia esta situación, la crítica puede quedar relegada exclusivamente a la academia, perdiendo su posibilidad de tener un sentido práctico, de ser constructiva, tanto para la formación de la sociedad del momento como para aquellos que se dedican al ejercicio de la profesión:

If we are not careful, if critics don't assert their authority and attract an audience, if magazines and newspapers don't keep design and architecture in their culture sections, if new institutions aren't created online, architecture critique could disappear back into the academy. The uncertainty of the media landscape is part of the problem. For critics to do their job, they need a certain degree of security. Financial security, in the sense of someone to pay for their travel (if the architect pays, it creates an ethical quandary) and someone to pay for their words (to make it worth their while). But they also need institutional security to a point. Authority comes from expertise, it comes from developing a point of view over time, it comes from the audience expectations that a critic will be there to tell them what is what, but it also comes from others' support (párr.4).

[Si no tenemos cuidado, si los críticos no afirman su autoridad y atraen al público, si las revistas y los periódicos no mantienen el diseño y la arquitectura en sus secciones culturales, si no se crean nuevas instituciones online, la crítica de arquitectura podría desaparecer y quedar relegada a la academia. La incertidumbre del panorama de los medios es parte del problema. Para que los críticos hagan su trabajo, necesitan un cierto grado de seguridad. Seguridad financiera, en el sentido de que alguien pague por su viaje (si el arquitecto paga, crea un dilema ético) y alguien que pague por sus palabras (para que valga la pena). Pero también necesitan seguridad institucional hasta cierto punto. La autoridad viene de la pericia, viene del desarrollo de un punto de vista en el tiempo, viene de las expectativas del público de que un crítico estará ahí para decirles qué es qué, pero también viene del apoyo de otros].

La seguridad económica e institucional que describe Lange es clave para que un crítico pueda ejercer su papel de manera independiente y evitar, así, que su labor crítica pueda verse manipulada por determinadas presiones externas u obedezca a intereses ocultos. Como escribió el arquitecto e historiador Joseph Rykwert (2014) en la revista italiana Domus: 
The critic must be a fighter. To do so, critics must of course have a base from which to operate -not only the obvious one of a newspaper, periodical, radio or television programme or even a blog that will make their views public, but they must, more intimately, have a clearly articulated notion of what they think society must expect of its builders, meaning not only architects, but also building speculators, developers, local and central government-, in fact, all those who frame the programmes by which the architect must operate (párr.7).

[El crítico debe ser un luchador. Para ello, los críticos deben tener, por supuesto, una base desde la que operar -no sólo la obvia de un periódico, una revista, un programa de radio o televisión o incluso un blog, que hará públicas sus opiniones, pero además deben tener una noción claramente articulada sobre lo que piensan que la sociedad debe esperar de sus constructores, es decir, no sólo de los arquitectos, sino también de los especuladores de la construcción, los promotores, el gobierno local y central-, de hecho, de todos los que enmarcan los programas por los que el arquitecto debe operar].

Una vez más, vuelve a aparecer con esta cita la importancia del contexto económico, político y social que el crítico tiene la obligación de conocer y al que siempre debe hacer referencia para establecer sus juicios con fundamento. En este mismo texto, Rykwert (2014) expone que el crítico puede imbuirse todavía más en dicho contexto interactuando de manera directa con los propios ciudadanos y habitantes del entorno o un edificio en concreto: "Further, the critic is justified in enquiring about how the building is perceived both by users and the general public, since all such reactions do form part of any critical arsenal" [Además, se justifica que el crítico pregunte cómo perciben el edificio los usuarios y el público en general, ya que todas esas reacciones forman parte de cualquier arsenal crítico] (párr.6). Un claro ejemplo de este último perfil de crítico de arquitectura al que Rykwert hace referencia fue la estadounidense Jane Jacobs. La influencia de la redactora de la revista Architectural Forum traspasaba las fronteras del papel, dejando a la luz su faceta más activista (por ejemplo, Jacobs se involucró junto a un gran número de vecinos del West Village para paralizar la construcción de la autovía conocida como la Lower Manhattan Expressway). Con su modo de concebir su trabajo, Jacobs demostró que un crítico de arquitectura que logra trasladar las necesidades de la ciudadanía a los medios de comunicación social contribuye significativamente a que dichos ciudadanos velen por la ciudad que habitan.

Alexandra Lange en su libro Writing about architecture (2012) cita también a Jacobs como ejemplo de crítica que realiza un enfoque de tipo "activista" en sus textos. Además, Lange en ese mismo libro expone otros tres tipos de enfoques que definen a los críticos. El primero de ellos que cita (poniendo como ejemplos a los críticos neoyorquinos Ada Louise Huxtable y Lewis Mumford) es el "formal", aquel que hace énfasis:

On the visual: the building or object's form. Both Huxtable and Mumford come to their judgments through intense looking. They write about what they see from the street: the building's organization, materials, connections. They literally walk you through the building, describing and picking at it as they go, suggesting improvements (10).

[En lo visual: la forma del edificio o del objeto. Tanto Huxtable como Mumford llegan a sus juicios a través de una mirada intensa. Escriben sobre lo que ven en la calle: la organización del edificio, los materiales, las conexiones. Literalmente te pasean por el edificio, describiéndolo y recogiéndolo a medida que avanzan, sugiriendo mejoras]. 
El segundo tipo de enfoque que menciona (citando al crítico estadounidense Herbert Muschamp) es el “experiencial”:

Created and defined by Muschamp, the late New York Times critic. Muschamp is also descriptive in his writing, but he expresses the way a building makes him (and by extension, the reader) feel. His reviews can start anywhere in a building and often mix in other media -movies, art, books, poetry- in order to make the emotional connection between architecture and reader (10).

[Creado y definido por Muschamp, el fallecido crítico del New York Times. Muschamp también es descriptivo en su escritura, pero expresa la forma en que un edificio lo hace sentir (y por extensión, al lector). Sus críticas pueden comenzar en cualquier lugar de un edificio y a menudo se mezclan con otros medios -películas, arte, libros, poesía- para establecer una conexión emocional entre la arquitectura y el lector].

Y el tercer enfoque, y último en este caso (ya que el cuarto mencionado por Lange es el "activista" que se ha comentado anteriormente), es el "histórico", que define como aquel que es:

Primarily identifiable in the work of the critic Paul Goldberger. He is interested in the architect's career and in fitting buildings within that (limited) framework. A Goldberger review may be as much about personality and presence on the world stage as it is about a building, but it also offers a sense of context missing from other critics' work. One is left with a sense of completeness, of having a thorough survey (10-11).

[Principalmente identificable en el trabajo del crítico Paul Goldberger. Se interesa por la carrera del arquitecto y en evaluar los edificios dentro de ese (específico) marco. Una crítica de Goldberger puede tratar con el mismo detalle, tanto la personalidad y la presencia en el escenario mundial del arquitecto, como el propio edificio, pero esto también ofrece una sensación de contexto que falta en el trabajo de otros críticos. Uno se queda con una sensación de plenitud, de tener un estudio exhaustivo].

Esta manera sucinta de clasificar y describir los distintos enfoques que puede tomar el crítico a la hora de escribir el texto es sumamente reveladora para tratar de comprender los distintos modos de abordar la arquitectura a través de la crítica. Por otro lado, es fundamental que, al mismo tiempo, los medios cotejen lo que están difundiendo y tengan siempre conocimiento de estas dos cuestiones señaladas por el arquitecto y profesor Eduardo Prieto (2019): “ ¿Quién es el crítico? ¿Para quienes escriben los críticos? Las respuestas a estas preguntas no solo definen el arte o la arquitectura contemporáneas; definen también la propia sociedad" (63). Y por extensión, los periódicos también tienen que preguntarse quiénes son los periodistas y para quienes escriben, más aún en la actualidad, ya que un gran número de ellos son freelance o colaboradores externos y, por tanto, no trabajan en las redacciones.

\subsection{Profesionales que escriben los textos}

A fin de conocer con exactitud en esta investigación quiénes son los críticos y quiénes son los periodistas responsables de los contenidos de arquitectura en ABC.es se han recogido en la Tabla 5 los nombres de los profesionales que más han escrito sobre esta disciplina en el periodo analizado, especificando el número de textos publicados por cada uno de ellos, tanto mes a mes como en todo el semestre. 
Tabla 5. Autores de los textos de "Arquitectura" de ABC.es en 2019

\begin{tabular}{|l|c|c|c|c|c|c|c|}
\hline $\begin{array}{l}\text { Autores de los textos de } \\
\text { “Arquitectura” de } \text { ABC.es en 2019 }\end{array}$ & Enero & Febrero & Marzo & Abril & Mayo & Junio & Total \\
\hline Redacción & 3 & 2 & 4 & 2 & 4 & 2 & $\mathbf{1 7}$ \\
\hline Adrián Delgado & 0 & 0 & 1 & 0 & 1 & 1 & $\mathbf{3}$ \\
\hline Belén Rodrigo & 3 & 3 & 4 & 4 & 4 & 3 & $\mathbf{2 1}$ \\
\hline Fredy Massad & 2 & 0 & 4 & 4 & 7 & 1 & $\mathbf{1 8}$ \\
\hline Javier Díaz-Guardiola & 0 & 0 & 0 & 2 & 1 & 0 & $\mathbf{3}$ \\
\hline Marta R. Domingo & 1 & 0 & 1 & 2 & 0 & 0 & $\mathbf{4}$ \\
\hline Paloma Santamaría & 0 & 1 & 2 & 0 & 1 & 1 & $\mathbf{5}$ \\
\hline EFE & 0 & 0 & 0 & 2 & 0 & 2 & $\mathbf{4}$ \\
\hline
\end{tabular}

Fuente: elaboración propia

Al observar la Tabla 5, se puede ver que los profesionales que más han publicado han sido, con gran diferencia: Belén Rodrigo -21 textos-, Fredy Massad -18 textos- y, en tercer lugar, los 17 textos que figuran sin firma de autor, indicándose exclusivamente el nombre de la redacción del propio diario o de sus respectivas publicaciones. Esto último es habitual cuando se trata de textos informativos, de poca extensión, que proceden de notas de prensa o comunicados de fuentes oficiales. Los otros nombres de la tabla han escrito como máximo en cinco ocasiones. No obstante, mucho más que el resto de profesionales que no se han incluido y que se citan a continuación. Y es que, aunque la suma total de firmas asciende a 45, 37 de las ellas han publicado una o dos veces en todo el semestre. Tan solo dos textos: César Justel, Juan Pedro Quiñonero, M.C., S. L. y Sara Medialdea. O exclusivamente una publicación: Jorge Bustillo, Laura Peraita, Juan Francisco Rueda, María I. Ortiz, M. N., D. Morán, J. F. Alonso, Jesús Fuentes, Isabel Lázaro, J. L.Fernández, Lefteris Karagiannopoulos, Carlos Lameda, Bruno Pardo Porto, Rosalía Sánchez, Ignacio.S.Calleja, Adoney Bermúdez, Paola Rodríguez, Begoña Castiella, David Alandete, Mar Sánchez-Cascado, Valle Sánchez, Sergi Doria, H. Díaz, Fernando Blasco, Pedro Gargantilla, Ángel Gómez Fuentes, Lourdes Gómez, Silvia Nieto, Natividad Pulido, Agencias, Reuters y Europa Press.

Al consultar los perfiles profesionales de aquellos que más textos han escrito sobre arquitectura, Belén Rodrigo y Fredy Massad, se ha comprobado que los dos tienen una formación distinta, pero, en ambos casos, especializada en la disciplina sobre la que escriben. Por un lado, Belén Rodrigo (Segovia, 1977) es licenciada en Periodismo por la Universidad Complutense de Madrid y en Historia por la UNED. Actualmente, trabaja como periodista en ABC.es publicando reportajes sobre edificios históricos de la capital que documenta con sus propias fotografías. Por otro lado, Fredy Massad (Banfield, Buenos Aires, 1966) es arquitecto por la Universidad de Buenos Aires (Argentina) y profesor de la asignatura Teoría y Crítica de la Arquitectura en la Escuela Técnica Superior de Arquitectura de la UIC en Barcelona. Además, de escribir en el diario, es el crítico de arquitectura del suplemento $A B C$ Cultural y autor del blog de arquitectura La viga en el ojo de $A B C$. es. Por tanto, ambos tienen una formación profesional especializada en el tipo de contenidos sobre los que escriben. 


\subsection{Diseño web y recursos visuales y audiovisuales}

Un factor que influye, sin duda, en la lectura de las publicaciones es el diseño web. La apariencia del menú de los textos etiquetados como "Arquitectura" en $A B C$.es se detalla en la siguiente imagen [Fig.2]:

Figura 2. Menú de temas etiquetados como "Arquitectura" en ABC.es

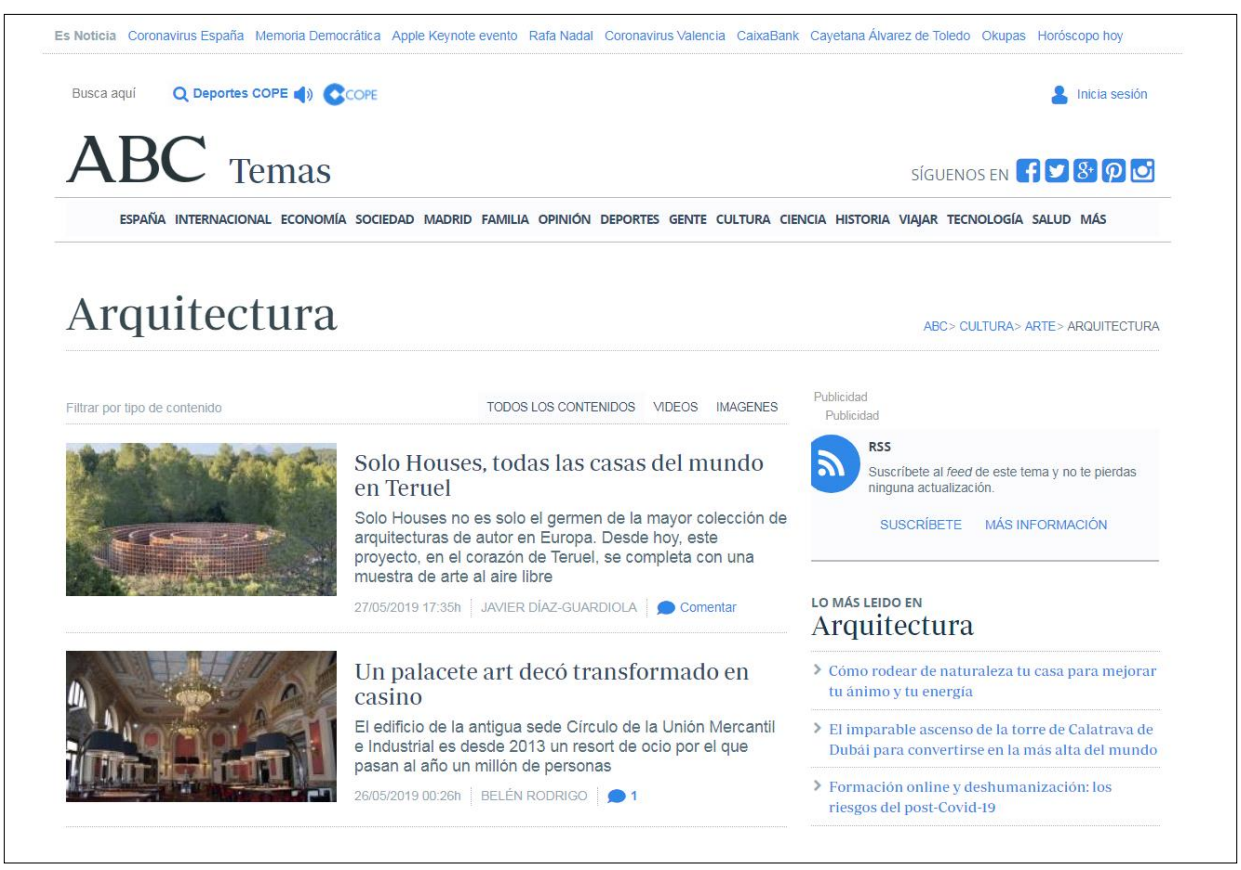

$\mathrm{Al}$ hacer clic sobre un texto, el contenido aparece estructurado acorde al diseño que se muestra en la siguiente imagen [Fig.3]: 
Figura 3. Ejemplo de texto de arquitectura de la versión digital de ABC Cultural publicado el 9 de mayo de 2019

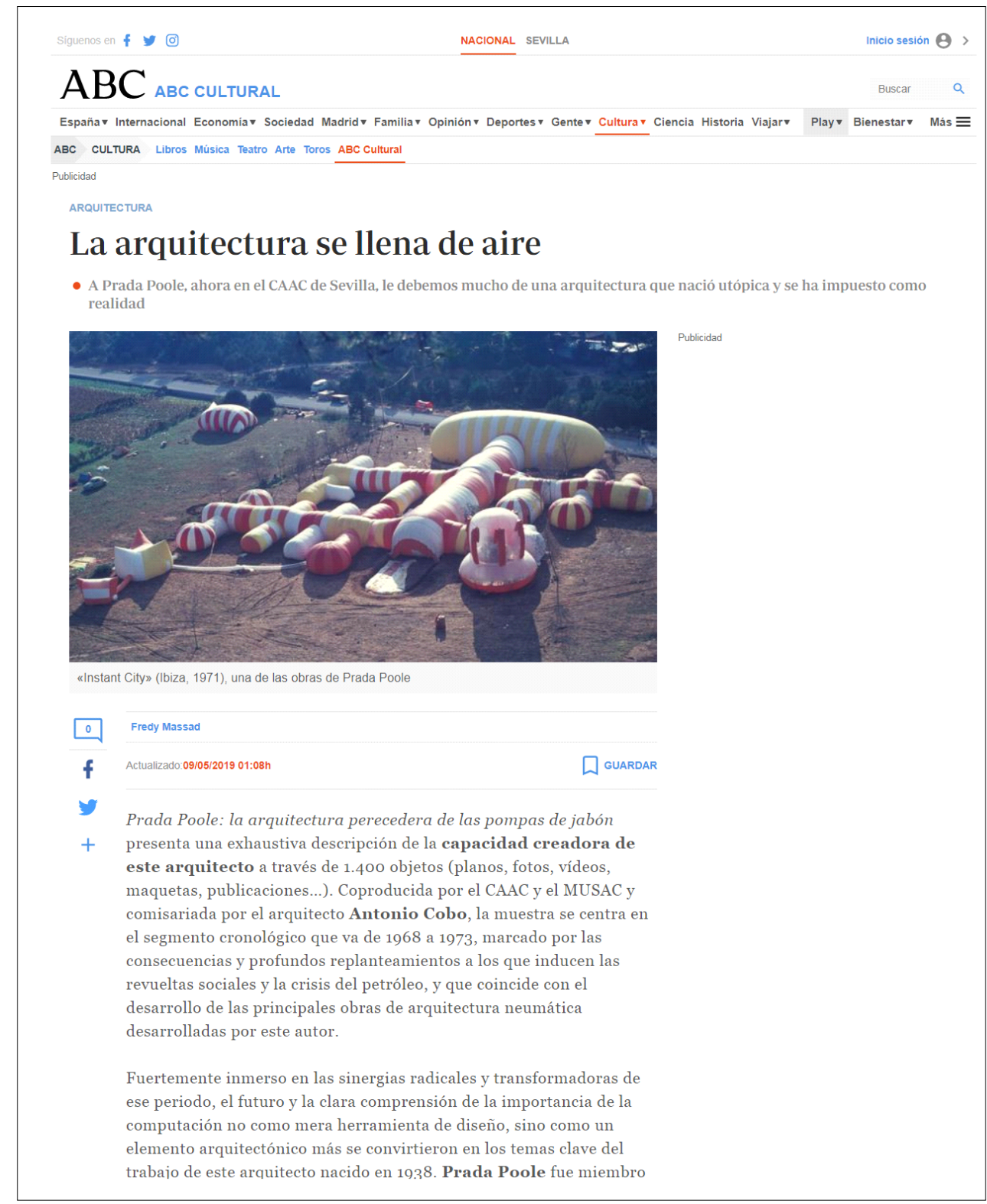


Cuando se escribe sobre disciplinas en las que el factor visual es enormemente importante, como es el caso del arte y la arquitectura: "no podemos olvidarnos de las imágenes. Lo normal es que hagamos discursos sobre cosas que 'pueden verse', y es muy frecuente que algunas reproducciones de cosas concretas sean esenciales para que el argumento que se va a desarrollar resulte comprensible" (Ramírez, 2014: 31). Por este motivo, este tipo de textos suelen estar ilustrados por varias imágenes o galerías de imágenes que permitan conocer, por ejemplo, el diseño de la fachada de un edificio y las partes más destacadas de su interior, etc. Además, el soporte digital cuenta, a diferencia de las publicaciones en papel, con la gran ventaja de tener un espacio ilimitado, que posibilita incluir tantas imágenes como se desee.

A fin de conocer con exactitud el número de imágenes que han ilustrado los textos de arquitectura se ha elaborado la Tabla 6, en la que se detalla no solo el número total de imágenes que se han publicado cada mes, sino también, entre paréntesis, el número de las que han aparecido en cada texto.

Tabla 6. Imágenes de los textos de "Arquitectura" de ABC.es en 2019

\begin{tabular}{|c|c|c|c|c|c|c|}
\hline \multicolumn{7}{|c|}{ Imágenes en los textos de "Arquitectura" de $A B C . e s$ en 2019} \\
\hline Enero & Febrero & Marzo & Abril & Mayo & Junio & Total \\
\hline $\begin{array}{c}38 \\
(1+4+2+5+6+1+ \\
1+3+2+9+4)\end{array}$ & $\begin{array}{c}28 \\
(2+6+3+2+ \\
5+1+6+1+2)\end{array}$ & $\begin{array}{c}65(4+5+7+4+1 \\
+2+3+3+5+6+3 \\
+2+1+3+1+6+3 \\
+1+5)\end{array}$ & $\begin{array}{l}53(2+1+2+1+5+ \\
4+1+2+2+3+5+1 \\
+5+2+3+4+5+5)\end{array}$ & $\begin{array}{c}63(3+2+3+5+2+ \\
4+6+2+7+1+1+3 \\
+6+1+2+1+5+3+ \\
1+4+1)\end{array}$ & $\begin{array}{c}51(1+1+5+4+1+ \\
11+5+1+1+4+1+ \\
2+3+1+1+5+4)\end{array}$ & 298 \\
\hline
\end{tabular}

Fuente: elaboración propia

Como se observa en la Tabla 6, todos los textos que se ilustran con imágenes tienen al menos una (los pocos textos que no tienen imágenes insertadas a lo largo del contenido cuentan con una galería de imágenes o un vídeo). Incluso hay bastantes publicaciones que tienen más de cuatro imágenes, unas cifras que son propias de contenidos altamente visuales. En total, se han publicado, en el primer semestre, 298 imágenes con los textos de arquitectura. No obstante, a este número hay que sumarle las incluidas en las galerías de imágenes, que se han contabilizado de manera independiente en la Tabla 7, detallando también entre paréntesis el número de imágenes de cada galería.

Tabla 7. Galerías de imágenes en los textos de "Arquitectura" de $A B C . e s$ en 2019

\begin{tabular}{|c|c|c|c|c|c|c|}
\hline \multicolumn{7}{|c|}{ Galerías de imágenes en los textos de “Arquitectura" de $A$ BC.es en 2019 } \\
\hline Enero & Febrero & Marzo & Abril & Mayo & Junio & Total \\
\hline 3 & 2 & 4 & 4 & 4 & 2 & 19 galerías \\
$(7+10+10)$ & $(5+10)$ & $(10+10+10+6)$ & $(10+10+12+10)$ & $(22+5+6+4)$ & $(13+14)$ & $(184$ imágenes $)$ \\
\hline
\end{tabular}

Fuente: elaboración propia 
Por tanto, a las 298 imágenes hay que añadir las 184 presentes en las 19 galerías que han acompañado también a los textos. De hecho, algunos de ellos se han ilustrado con imágenes y, además, con una galería de imágenes. Es decir, que en total se han publicado 482 imágenes para ilustrar los 117 textos de arquitectura del primer semestre del año 2019.

Al mismo tiempo, el soporte digital ofrece la posibilidad de hacer uso de recursos audiovisuales. Aunque es cierto que los vídeos son poco habituales, el diario también los ha utilizado en estos contenidos como complemento de la información ofrecida en determinados artículos. En la Tabla 8, se recogen por meses los vídeos que se han publicado a lo largo del periodo estudiado: siempre un vídeo por texto, aunque algunos textos incluyen, además del vídeo, imágenes o una galería de imágenes.

Tabla 8. Vídeos en los textos de "Arquitectura" de ABC.es en 2019

\begin{tabular}{|c|c|c|c|c|c|c|}
\hline \multicolumn{7}{|c|}{ Vídeos en los textos de “Arquitectura" de ABC.es en 2019} \\
\hline Enero & Febrero & Marzo & Abril & Mayo & Junio & Total \\
\hline 1 & 0 & 1 & 1 & 4 & 2 & 9 \\
\hline
\end{tabular}

Fuente: elaboración propia

Como se indica en la Tabla 8, en total, se han publicado 9 vídeos. Ninguno en febrero; uno, en los meses de enero, marzo y abril; dos en junio y cuatro en mayo. Por lo que se puede afirmar que, casi todos los meses, encontramos un tema de arquitectura con vídeo.

\section{Conclusiones}

La presente investigación ha permitido conocer el tratamiento de los contenidos etiquetados como "Arquitectura" en ABC.es. A partir de la muestra estudiada se han extraído varias conclusiones. La primera de ellas es que el número de textos etiquetados como "Arquitectura", que se han publicados en el año 2019, es similar en ambos semestres: 117 en el primero y 111 en el segundo. En cambio, el número mensual de textos dedicados a esta disciplina ha sido bastante variable: oscilando entre los 11 publicados en el mes de febrero y los 27 en el mes de mayo. Además, hay que mencionar que, aunque la web del diario tiene un diseño claro, el acceso a estos textos solo se puede realizar introduciendo en el buscador el nombre de la temática y no a través del menú de secciones. Es decir, que en $A B C$.es no hay un acceso directo a los contenidos de arquitectura (a diferencia de lo que ocurre en ElPaís.com, que incluye en el menú de su sección de cultura una pestaña dedicada exclusivamente a esta disciplina, aunque bien es cierto que es el único periódico español que la tiene).

En este estudio ha sido interesante comprobar, en primer lugar, cómo para analizar en profundidad el estado actual de la arquitectura en este periódico era importante no centrarse solo en los textos publicados en la sección de cultura y en el suplemento, ya que este tipo de contenidos tienen también una gran relevancia en la sección Madrid que, de hecho, es la que mayor número de ellos ha publicado -33 textos-, representando un $28 \%$, frente al $21 \%$ de la sección de cultura o el $18 \%$ del suplemento $A B C$ Cultural. 
Dentro de los textos de arquitectura, se han creado exprofeso para este estudio distintas categorías que ayudan a definir mejor los contenidos. Entre ellas, las más populares han sido “Edificios” y “Patrimonio", casualmente ambas con 39 textos, por lo que representan el mismo porcentaje: un 33\% cada una. De ello se puede deducir que $A B C$.es da la misma importancia a los edificios contemporáneos, que a los antiguos. Esta variedad es interesante a nivel cultural, ya que incentiva la atracción de lectores con distintos perfiles. Por otro lado, los textos de las disciplinas que pueden considerarse afines a la arquitectura, como el interiorismo y el diseño, suponen cada una un $3 \%$, unos porcentajes bastante reducidos dentro de este tipo de contenidos.

El estudio de los géneros también ofrece unos datos muy reveladores sobre el tratamiento de los contenidos de arquitectura. Por ejemplo, se ha comprobado que el 38\% de los textos son noticias, es decir, que tienen como misión puramente informar. Por el contrario, las críticas, que exigen a los profesionales que las escriben la emisión de juicios de valor y la reflexión a partir de la teoría propia de la materia, representan tan solo el 5\% del total. Un porcentaje muy reducido, que debería ser mayor, ya que la arquitectura tiene una gran repercusión en la vida de las personas y, por tanto, es verdaderamente importante no solo informar, sino reflexionar sobre ella en los medios. Aunque, por otro lado, hay que destacar de manera positiva el elevado número de reportajes que se ha publicado a lo largo del semestre, concretamente 27, que representan el $23 \%$ del total. Este tipo de textos son muy enriquecedores porque tratan una temática reuniendo los puntos de vista de distintas voces. No obstante, es una lástima que solo se realicen -o al menos en estos seis meses analizados así ha sido-sobre edificios que forman parte del patrimonio, la inmensa mayoría de ellos sobre palacetes de Madrid, y no haya más sobre edificios o proyectos contemporáneos. Asimismo, se ha comprobado que es bastante elevado el número de textos construidos exclusivamente a base de galerías de imágenes y tipo test: 16 que suponen el 14\% (clasificados como "Otros" en el Gráfico 3). Más aun teniendo en cuenta que un gran número de ellos se publican dentro de la sección de cultura o en el suplemento $A B C$ Cultural. Sin duda, un claro ejemplo de la obsesión que existe en los medios digitales por el clickbait.

Respecto al perfil de los profesionales que más han escrito sobre arquitectura en $A B C$.es se ha confirmado que, tanto Belén Rodrigo -21 textos-, como Fredy Massad -18 textos-, tienen una formación especializada en la materia. No obstante, se debería ampliar la frecuencia con la que escriben algunos de los otros profesionales, aunque se tenga que reducir su número, a fin de que los lectores tuvieran más referentes en la materia. Y es que los 117 textos analizados han sido publicados por 45 autores distintos, pero 37 de ellos solo han escrito una o dos veces en todo el semestre.

Por último, se ha comprobado que la suma del número de imágenes y de las galerías de imágenes, que ilustran los contenidos de esta disciplina, da un total de 482 imágenes entre los 117 textos. Una cifra que todavía podría ser más elevada si todos los textos tuvieran más de una imagen. Por el contrario, el vídeo es un recurso mucho menos utilizado. Aunque casi todos los meses se ha publicado alguno, la cifra total en el primer semestre es solo de nueve, y debería ser mayor para aprovechar las distintas posibilidades que ofrece el soporte digital. 


\section{Referencias bibliográficas}

Goldberger, P. (2007, 8 de octubre). Writing About Architecture. Yale School of Architecture. Recuperado de https://www. paulgoldberger.com/lectures/writing-about-architecture/

Goldberger, P. (2012). Por qué importa la arquitectura. Madrid: Ivorypress

Grijelmo, A. (2014). El estilo del periodista. Madrid: Taurus

Lange, A. (2010, 7 de enero). Whatever Happened to Architecture Critique? Design Observer. Recuperado de https://designobserver.com/feature/whatever-happened-to-architecture-critique/22808

Lange, A. (2012). Writing About Architecture: Mastering the Language of Buildings and Cities. Nueva York: Princeton Architectural Press

López, X. (2004) Información Cultural. En J. Fernández del Moral (Coord.), Periodismo especializado (pp. 377-396). Barcelona: Editorial Ariel

Montaner, J. M. (2013). Arquitectura y crítica. Barcelona: Editorial Gustavo Gili

Prieto, E. (2019). Crítica \& Público. En D. Rivera y E. Prieto (coords.), Crítica \& Crisis. El autor, el público, la arquitectura (pp. 14-63). Madrid: Ediciones Asimétricas

Quesada, M. (2012). Curso de periodismo especializado. Madrid: Editorial Síntesis

Ramírez, J. A. (2014). Cómo escribir sobre arte y arquitectura: libro de estilo e introducción a los géneros de la crítica y de la historia del arte. Barcelona: Ediciones del Serbal

Rodríguez Pastoriza, F. (2006). Periodismo cultural. Madrid: Síntesis

Ruiz Mantilla, J. y Garbisu Buesa, M. (2019). Cultura y periodismo escrito. En M. Garbisu Buesa e I. Blanco Alfonso (Eds.), Periodismo Cultural (pp. 17-42). Madrid: Ediciones CEF.

Rykwert, J. (2014, 21 de mayo). Does architecture criticism matter? Domus. Recuperado de https://www.domusweb.it/en/ opinion/2014/05/21/does_architecturecriticismmatter.html 